\title{
BUILDING HEALTH SYSTEM RESILIENCE DURING COVID-19 CRISIS
}

\author{
Membangun Resiliensi Sistem Kesehatan Selama Krisis COVID-19 \\ ${ }^{*}$ Amanatul Ainiyah Firda1, Setya Haksama1 \\ ${ }^{1}$ Department of Health Policy and Administration, Faculty of Public Health, Universitas Airlangga \\ ${ }^{*}$ Correspondence: amanatul.ainiyah.firda-2016@fkm.unair.ac.id
}

\begin{abstract}
Received: 15 April 2020
Coronavirus is a type of virus that causes long-term health threats because coronavirus can adapt to new environments through mutations and recombination which is relatively simple ( $\mathrm{Li}, 2016)$. Whereas in 2019, a new type of coronavirus was founded and known as the COVID-19 pandemic (Guarner, 2020). The COVID-19 pandemic has resulted not only in the high number of infected people and the number of deaths but also in the social, cultural, and economic fields (Uddin et al., 2020). To reduce the impact of the crisis recurrence, it is necessary to reduce risks and build resilience systems (United Nations Secretariat for International Strategy for Disaster Reduction, 2012). One of the resilience systems that can deal with disasters, especially the coming crisis is a health system resilience (Kruk et al., 2015). Health system resilience is the ability of health workers, all institutions, and communities to prepare and respond to crises effectively by considering the experience of previous crises (Nuzzo et al., 2019).
\end{abstract}

Health system resilience works in a disaster, a crisis, or pandemic. The World Health Organization has created the International Health Regulations (IHR) Joint External Evaluation (JEE) tool in 2016. JEE is an important tool to assess the capacity of a country in dealing with infectious disease outbreaks and public health emergencies. The successful JEE can support the establishment of health system resilience (World Health
Organization, 2019). Although JEE has begun to develop, health facilities are still experiencing vulnerabilities in facing public health emergencies. The JEE does not explicitly assess how health care facilities overcome obstacles such as travel distance, high medical costs, and distrust of public (Nuzzo et al., 2019). Therefore, it takes a more detailed explanation regarding supporting factors to build health system resilience.

Kruk et al. (2017) mentioned health system resilience framework can overcome the outbreak. Health system resilience framework has several supporting factors, such as awareness, diversity, selfregulation, integration, and adaptation (Kruk et al., 2015). The implementation of health system resilience was one of the attempts to support Liberia to rise from the Ebola crisis (Kruk et al., 2015). According to Ling et al. (2017), an analysis of the implementation of health system resilience in the case of Ebola in Liberia refers to the health system resilience framework of Kruk et al. (2017) in which mentioned the coordination between participating actors and the community improved.

Participating actors in Liberia were also aware of enhancing disease surveillance and tracking. Actors who took over the health system in Liberia were selfregulated and aware of the outbreak by raising public awareness of th outbreak threats, giving greater autonomy to the local country health team. While governments and community leaders play 
a role in providing more health services to meet the community's needs.

The success of health system resilience due to Ebola can be used as a reference for dealing with the future crisis. In other words, health system resilience is important for every country during the COVID-19 pandemic. The Department for International Development UK has made a policy brief about principles of health system resilience for handling the COVID19. The principles consist of flexible system development for medical supplies, priority for COVID-19 healthcare services, cooperation with local communities, effective communication at all levels and involvement of supporting officers in handling COVID-19. Others include wellprovided facilities to support the acceleration of resource flows in all healthcare services, quick health information tracking, and expansion of partnerships and effective networks (Department for International Development, 2020).

Health system resilience can protect human life during and after a crisis. Besides, health system resilience can make more effective services and stronger methods to deal with future crises. According to Legido-Quigley et al. (2020), Japan, Singapore, and Hong Kong tried to build health system resilience to face the COVID-19 outbreak by learning from the previous crises, such as SARS-CoV, H5N1 Avian Influenza, and H1N1 influenza. They implemented appropriate measures in national security and governance structures, took steps to support the availability of healthcare services and give funding for healthcare services, and developed existing management plans and structures.

Nevertheless, these countries had deficient health system resilience in confronting the COVID-19 outbreak. For example, they lacked coordination in providing services, access and provision of medical equipment, ineffective communication, and low public confidence in the government. In short, health system resilience during crisis exists when there is more integration of services in healthcare systems and across sectors, less false news and incorrect information, and higher public confidence in the government that ensures the crisis management.

\section{REFERENCES}

Ager, A. and Toltica, S. (2020) Principles of Health Systems Resilience in the Context of Covid-19 Response. Available at: https://www.gov.uk/dfidresearch-outputs/principles-ofhealth-systems-resilience-in-thecontext-of-covid-19-response.

Guarner, J. (2020) 'Three Emerging Coronaviruses in Two Decades The Story of SARS, MERS, and Now COVID-19', American Journal of Clinical Pathology, 153(4), pp. 420421. doi: 10.1093/AJCP/AQAA029.

Kruk, M. E. et al. (2015) 'What is a resilient health system? Lessons from Ebola', The Lancet. Elsevier Ltd, 385(9980), pp. 1910-1912. doi: 10.1016/S01406736(15)60755-3.

Kruk, M. E. et al. (2017) 'Building resilient health systems: A proposal for a resilience index', BMJ (Online), 357(j2323), pp. 1-8. doi: 10.1136/bmj.j2323.

Legido-Quigley, H. et al. (2020) 'Are highperforming health systems resilient against the COVID-19 epidemic?', The Lancet. Elsevier Ltd, 395(10227), pp. 848-850. doi: 10.1016/S0140-6736(20)30551-1.

$\mathrm{Li}, \quad F$. (2016) 'Structure, Function, and Evolution of Coronavirus Spike Proteins', Annual Review of Virology, 3(1), pp. 237-261. doi: 10.1146/annurev-virology-110615042301.

Ling, E. J. et al. (2017) 'Beyond the crisis: 
Did the Ebola epidemic improve resilience of Liberia's health system?', Health Policy and Planning, 32(suppl_3, pp. iii40--iii47. doi: $10.1093 / \mathrm{heapol} / \mathrm{czx} 109$.

Nuzzo, J. B. et al. (2019) 'What makes health systems resilient against infectious disease outbreaks and natural hazards? Results from a scoping review', BMC Public Health. BMC Public Health, 19(1310), pp. 19. doi: 10.1186/s12889-019-7707-z.

Uddin, M. et al. (2020) 'SARS-CoV2/COVID-19: Viral Genomics, Epidemiology, Vaccines, and Therapeutic Interventions', Viruses, 12(5), pp. 1-18. doi: 10.20944/PREPRINTS202004.0005. V1.

United Nations Secretariat for International Strategy for Disaster Reduction (2012) Disaster risk and resilience: Thematic think piece, Coronavirus (COVID-19). Available at: http://www.un.org/millenniumgoals/p $\mathrm{df} /$ Think.

World Health Organization (2019) Successful joint external evaluation preparatory meeting builds health system resilience in Iraq, International Health Regulations (IHR). Available at: http://www.emro.who.int/fr/internatio nal-healthregulations/actualites/joint-externalevaluation-preparatory-meetingbuilds-health-system-resilience.html (Accessed: 28 April 2020). 